Casos Clínicos

Arch. Esp. Urol. 2010; 63 (1): 74-77

\title{
FISTULA RENOCÓLICA COMO COMPLICACIÓN DE RADIOFRECUENCIA PARA TRATAMIENTO DE CARCINOMA RENAL DE CÉLULAS CLARAS
}

Javier Sáenz Medina, Enrique Redondo González, José Miguel Hernández-Atance, Luis Crespo Martínez, Luis Llanes González, David Rendón Sánchez y Alvaro Páez Borda.

Servicio de Urología. Hospital de Fuenlabrada. Madrid. España.

Resumen.- OBJETIVO: Describir un caso clínico de fístula reno cólica como complicación de ablación por radiofrecuencia de carcinoma de células renales. Se revisa la literatura y se exponen las diferentes actitudes diagnósticas y terapéuticas.

Javier Sáenz Medina

Lope de Vega 2, portal 5 1으

Pozuelo de Alarcón.

28223 Madrid (España)

javiersaenzmedina@yahoo.es

Trabajo recibido: 2 de julio 2009. 
MÉTODO: Tras la sospecha postoperatoria se realizó pielografía retrograda, cuyas imágenes se muestran, que demuestra la fístula.

RESULTADO: El tratamiento definitivo ha sido la nefrectomía tras intento fallido de sellar la fístula con sutura y tachosil.

CONCLUSIÓNES: Si bien la ablación por radiofrecuencia puede ser una técnica válida para el tratamiento del tumores renales de pequeño tamaño en pacientes con elevada morbilidad, no está exenta de complicaciones importantes como la descrita en este caso, a pesar de las precauciones tomadas.

Palabras clave: Ablación por radiofrecuencia. Tumores renales. Fístula.

Summary.- OBJECTIVES: To describe a clinical case of renocolic fistula as a complication of radiofrequency ablation of renal cell carcinoma. We reviewed the literature and presented different diagnostic and therapeutic approaches.

METHOD: Beyond postoperative suspicion, retrograde pyelogram was performed, the images of which are displayed, and demonstrated the fistula.

RESULTS: Treatment has been definitive nephrectomy after failed attempt to seal the fistula with suture and TachoSil.

CONCLUSIONS: Although radiofrequency ablation can be a valid technique for treating small renal tumors in patients with high morbidity, it is not without significant complications as described in this case, despite the precautions taken.

Keywords: Radiofrequency ablation. Renal tumors. Fistula.

\section{INTRODUCCIÓN}

La ablación por radiofrecuencia es una técnica utilizada para el tratamiento de masas renales de pequeño tamaño (menores de $3 \mathrm{cms}$ ), sobre todo en pacientes con comorbilidad asociada. No existen series amplias de enfermos que permitan conocer los resultados de la técnica, si bien se han publicado tasas de supervivencia libres de enfermedad del 90 al $97 \%$, con medianas de seguimiento que varían de 13,8 a 61,6 meses (1).

La tasa de complicaciones se sitúa entre el 2,8 y el $17,6 \%$, siendo la mayoría de ellas menores. Entre las complicaciones mayores destacan la hematuria macroscópica, la obstrucción ureteral, la lesión intestinal o la fístula calicial, la frecuencia de aparición se sitúa entre el 2,8 y el $3,1 \%(2)$.
La fístula renocólica es una entidad infrecuente que se suele asociar a enfermedades inflamatorias o tumorales del colon o del riñón. La mayoría de las publicadas están asociadas a pielonefritis xantogranulomatosa, entidad que ocasionalmente se extiende al espacio parrarrenal y puede afectar al aparato digestivo adyacente. En este caso se presenta como complicación de una ablación por radiofrecuencia en un paciente con riñón único, no hemos encontrado ninguna referencia bibliográfica respecto a esta complicación.

\section{MÉTODOS}

Se trata de un enfermo varón monorreno izquierdo sometido a dos nefrectomías parciales previas sobre su riñón único. Como consecuencia de una nueva recidiva (dos lesiones) fue objeto de un procedimiento de radiofrecuencia intraoperatoria (Figuras 1 y 2 ).

En el séptimo día tras la radiofrecuencia debutó con diarrea líquida importante, manteniendo una diuresis normal por la sonda vesical. No presentó fiebre ni alteraciones analíticas salvo por una elevación de la creatinina $(2,4 \mathrm{mg} / \mathrm{dl})$ que se correspondía con su creatinina basal, dada su insuficiencia renal crónica. Se realizó TAC de abdomen sin contraste en el que se objetivó la presencia de gas en la pelvis renal, así como una imagen compatible con una masa de aspecto tumoral a $3 \mathrm{cms}$ del margen anal (Figura 2). Una pielografía retrograda izquierda que demostró una fístula renocólica del caliz medio al colon descendente (Figura 3).

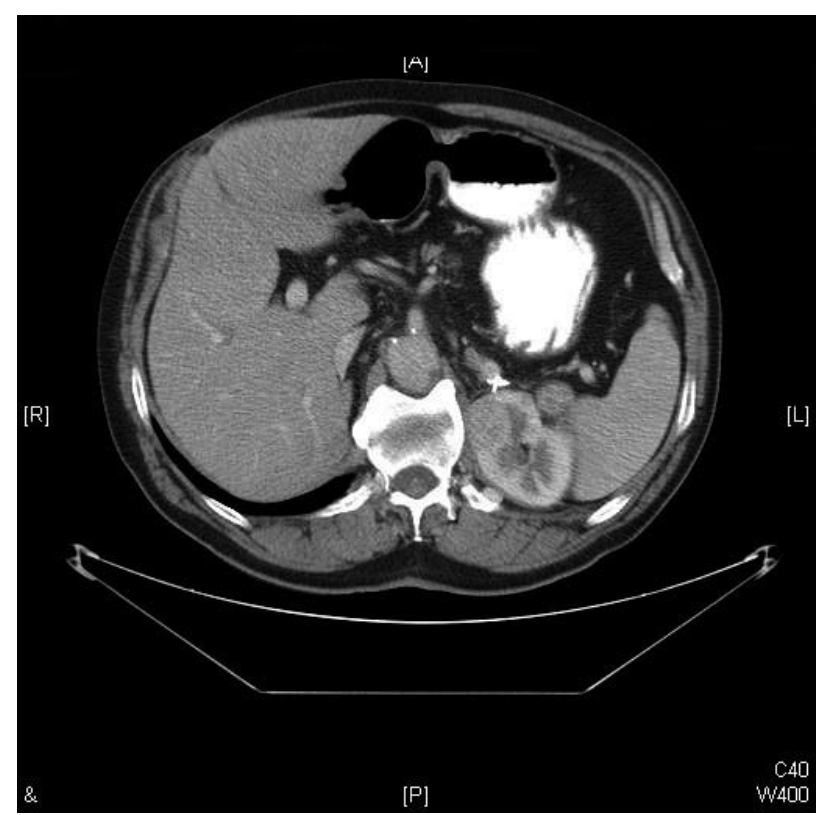

FIGURA 1. Corte axial de TAC abdominal. Imagen de tumor renal previo a ablación por radiofrecuencia. 


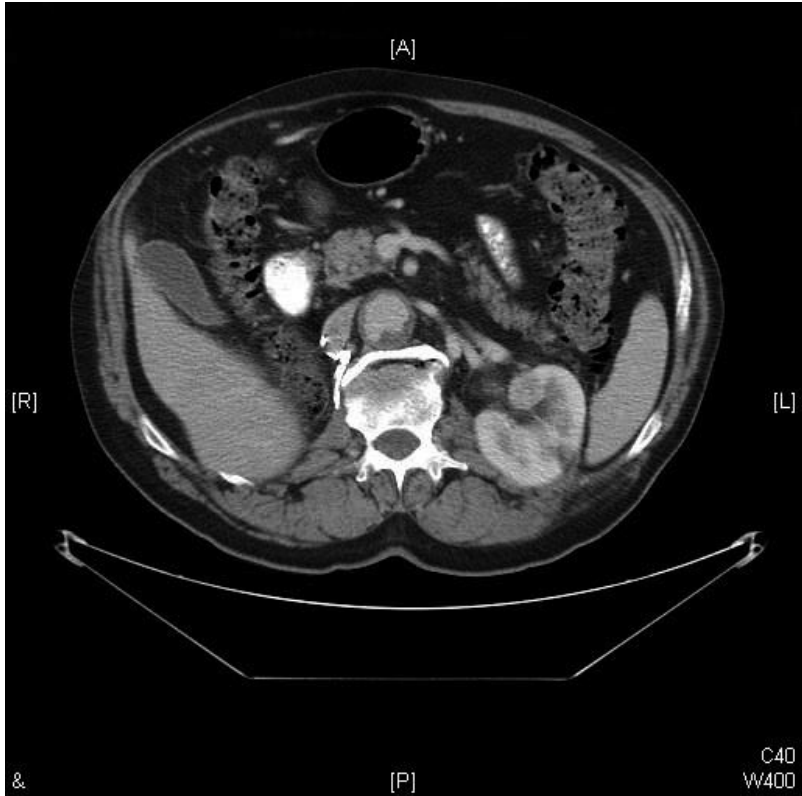

FIGURA 2. Corte axial de TAC abdominal. Imagen de tumor renal previo a ablación por radiofrecuencia

\section{RESULTADOS}

Con estos hallazgos se decidió tratar el tumor de colon mediante amputación abdominoperineal con extirpación añadida del colon descendente. Se identificó y se liberó el trayecto fistuloso reno cólico. Acto seguido se procedió a la sutura y sellado del parénquima con tachosil, y a la colocación de un doble J. Si bien en el postoperatorio inmediato la fístula pareció estar solucionada, en el cuarto día postoperatorio se evidenció la reapertura de la fístula a peritoneo; como primera medida se procedió a la nefrostomía percutanea por el caliz inferior; ante el nulo efecto de la derivación urinaria, se decidió la nefrectomía radical izquierda. El estudio anatomopatológico de la pieza de nefrectomía evidenció un carcinoma de células renales de células claras de patrón sólido grado nuclear I de Fuhrman.

\section{DISCUSIÓN}

La ablación por radiofrecuencia renal es una técnica validada para el tratamiento de las masas renales de pequeño tamaño en pacientes con comorbilidad importante asociada, ya que evita las complicaciones asociadas a la técnica quirúrgica. Consiste en la transferencia de corriente alterna monopolar de radiofrecuencia que provoca calentamiento, deshidratación y necrosis intracelular a través de agujas. Estas pueden ser insertadas vía abierta, laparoscópica o percutanea. Se ha demostrado "in vitro" que la muerte celular se produce a $60^{\circ} \mathrm{C}$ de forma instantanea y a $50^{\circ} \mathrm{C}$ durante $4-6$ minutos.

En cuanto a los resultados oncológicos, se han publicado cuatro series de pocos enfermos desde 2005. Las

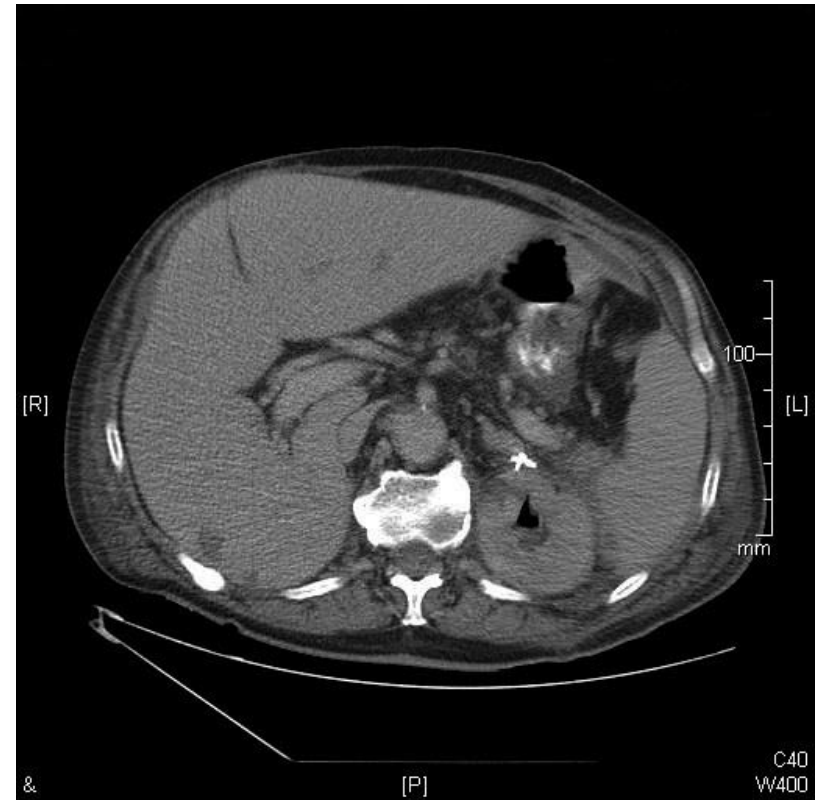

FIGURA 3. Corte axial de TAC abdominal. Imagen de aire en pelvis renal izquierda tras ablación.

medianas de seguimiento van desde los 28 meses de Gervais et al. (3), con una serie de 85 pacientes en los que consigue tasas libres de recurrencia del $90 \%$ en 85 pacientes con un tamaño medio del tumor de $3,2 \mathrm{cms}$, hasta los 61,6 meses de seguimiento de Levinson et al. (2) con una tasa libre de recurrencia del $90,3 \%$ en 31 pacientes con una tamaño tumoral medio de $2 \mathrm{cms}$. La serie de enfermos más larga la aportan Zagoria et al. (4) con 104 enfermos (mediana de seguimiento, 13,8 meses), en los que consigue una supervivencia libre de enfermedad del $93 \%$. La mejor supervivencia $(96,8 \%$ de tasa libre de recurrencia) la aporta Park (5), aunque

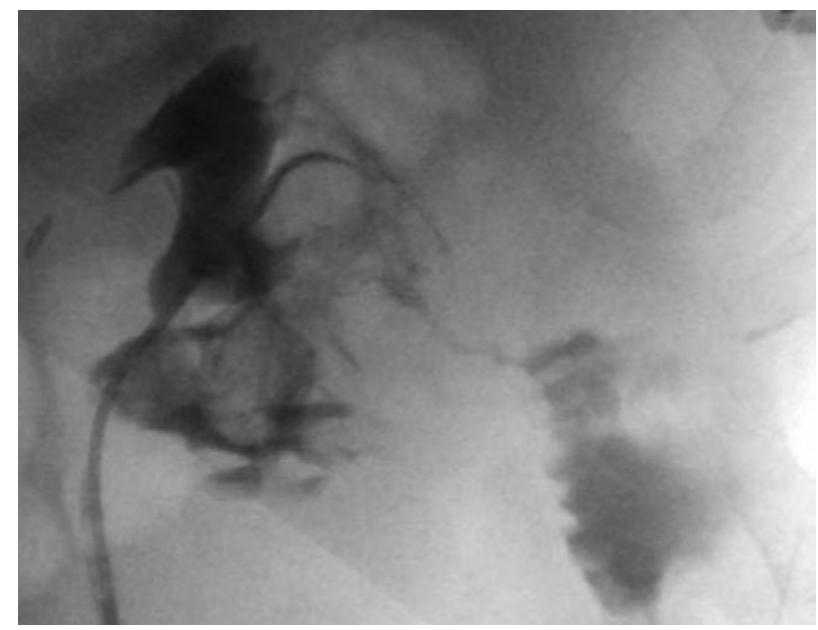

FIGURA 4. Pielografía retrógrada. Imagen de fístula cálicocolónica. 
con el seguimiento promedio mas corto $(n=78,13,8$ meses). Castillo et al presenta una serie con 12 enfermos a los que se realiza ablación por radiofrecuencia laparoscópica, previa realización de biopsia, tras 8 meses de seguimiento no refiere recidivas ni complicaciones, la estancia hospitalaria media fue de 25,8 horas (6).

En 2008 Lucas et al. (7) demostraron la menor afectación de la función renal producida por la ablación por radiofrecuencia en comparación con la nefrectomía parcial o la nefrectomía radical. Las posibilidades de progresar a una insuficiencia renal crónica estadío 3 con un seguimiento medio de 3 años era 11 veces superior que la ablación por radiofrecuencia para la nefrectomía parcial, y 34,3 veces para la nefrectomía radical. Dado que la ablación por radiofrecuencia se realiza en enfermos con comorbilidad importante en los que la función renal puede estar afectada, estos resultados cobran especial importancia.

La importante comorbilidad que presentaba nuestro enfermo, el fracaso en términos oncológicos que había supuesto las dos cirugías anteriores, el hecho de ser monorreno por un carcinoma renal, así como la insuficiencia renal crónica con creatininas en torno a $2,4 \mathrm{mg} / \mathrm{dl}$ nos hizo pensar en la ablación por radiofrecuencia como la mejor alternativa para el tratamiento del tumor. La multifocalidad del mismo así como la localización de los mismos y el difícil acceso percutáneo nos inclinó a usar la vía abierta (lumbotomía) como vía de acceso para una mejor liberación del mismo, intentando evitar de ese modo la lesión de órganos vecinos.

No existen series importantes que evalúen las complicaciones de la ablación por radiofrecuencia; las series expuestas anteriormente (2-4) sitúan la tasa de complicaciones entre el 2,8 y el $17,6 \%$, siendo la mayoría de ellas menores. La tasa de complicaciones mayores se sitúa entre el 2,8 y el 3,1\%, incluyendo la obstrucción ureteral, la lesión pielocalicial, la perforación intestinal - la hematuria importante que requiera maniobras terapéuticas (embolización, exploración...). Entre las complicaciones menores destacan las parestesias, hematurias leves, neumonías, hematomas perirrenales de pequeño tamaño, y complicaciones anestésicas; su proporción se sitúa entre el 3,5 y el $17,6 \%$.

\section{CONCLUSIONES}

En nuestro caso, no hemos encontrado publicada la fístula renocólica como complicación de la ablación por radiofrecuencia en el carcinoma renal de células claras. Consideramos, y coincidimos con la literatura, en que, si bien la ablación por radiofrecuencia puede ser una técnica válida para el tratamiento del tumores renales de pequeño tamaño en pacientes con elevada morbilidad, no está exenta de complicaciones importantes como la descrita en este caso, a pesar de las precauciones tomadas.

\section{BIBLIOGRAFÍA y LECTURAS RECOMENDADAS (*lectura de interés $y^{* *}$ lectura fundamental)}

*1. Carraway WA, Raman JD, Cadeddu JA, et al: Current status of renal radiofrequency ablation . Curr Opin Urol 2009; 19: 143.

*2. Levinson AW, Su LM, Agarwal D, et al: Long term oncological and overall outcomes of percutaneus radio frequency ablation in high risk surgical patients with a solitary renal mass. J Urol 2008; 180: 499.

*3. Gervais DA, Mc Govern FJ, Arellano RS, et al: Radiofrequency ablation of renal cell carcinoma. Part 1 : Indications, results, and role in patient management over 6 year- period and ablation of 100 tumors. Am J Roentgenol 2005; 185: 64.

*4. Zagoria RJ, Traver MA, Werle DM, et al: Oncologyc efficacy of CT guided percutaneus radiofrequency ablation of renal cell carcinomas. Am J Roentgenol 2007; 189: 429.

5. Park S, Anderson JK, Matsumoto ED, et al: Radiofrequency ablation of renal tumors: intermediateterm results. J endourol 2006; 20: 569.

**6. Velasco A, Castillo O, Vidal I, et al: Nephron-sparing surgery for the treatment of small renal tumors. The role of radiofrequency. Arch Esp Urol 2009; 62: 49.

7. Lucas SM, Stern JM, Adibi M, et al: Renal function outcomes in patients traeted for renal massessmaller yhan $4 \mathrm{cms}$ by ablative and extirpative techniques. $\mathrm{J}$ Urol 2008; 180: 499. 